\title{
Research Article \\ Electrochemiluminescence Study of Europium (III) Complex with Coumarin3-Carboxylic Acid
}

\author{
Stefan Lis, Krzysztof Staninski, and Tomasz Grzyb \\ Department of Rare Earths, Faculty of Chemistry, Adam Mickiewicz University, Grunwaldzka 6, 60780 Poznan, Poland \\ Correspondence should be addressed to Stefan Lis, blis@amu.edu.pl
}

Received 4 May 2008; Revised 12 June 2008; Accepted 22 July 2008

Recommended by Mohamed Sabry Abdel-Mottaleb

The europium (III) complex of coumarin-3-carboxylic acid (C3CA) has been prepared and characterized on the basis of elemental analysis, IR, and emission (photoluminescence and electrochemiluminescence) spectroscopy. The synthesised complex having a formula $\mathrm{Eu}(\mathrm{C} 3 \mathrm{CA})_{2}\left(\mathrm{NO}_{3}\right)\left(\mathrm{H}_{2} \mathrm{O}\right)_{2}$ was photophysically characterized in solution and in the solid state. Electrochemiluminescence, $\mathrm{ECL}$, of the system containing the Eu(III)/C3CA complex was studied using an oxide-covered aluminium electrode. The goal of these studies was to show the possibility of the use of electrochemical excitation of the $\mathrm{Eu}$ (III) ion in aqueous solution for emission generation. The generated ECL emission was very weak, and therefore its measurements and spectral analysis were carried out with the use of cut-off filters method. The studies proved a predominate role of the ligand-to-metal energy transfer (LMET) in the generated ECL.

Copyright (c) 2008 Stefan Lis et al. This is an open access article distributed under the Creative Commons Attribution License, which permits unrestricted use, distribution, and reproduction in any medium, provided the original work is properly cited.

\section{INTRODUCTION}

Coumarins and their derivatives due to their biological activities, interesting photophysical and photochemical, and metal binding properties have been a subject of numerous investigations [1-12]. This group of compounds is known to have diverse applications in biology and medicine, due to their anticancer, antibiotic, anticoagulant, and antiinflammatory $[1,2]$ properties. It has been found that the binding of a metal to the coumarin moiety retains or even enhances its biological activity $[2,3]$.

The coumarin-3-carboxylic acid (HC3CA) has previously been used as a ligand in complexation reactions with d-electron metal ions [5-7] and series of lanthanide cations (Dy(III), Er(III), Eu(III), Gd(III), Tb(III), and Sm(III)) [812]. The binding mode of coumarin-3-carboxylic acid in its La (III) complex has been investigated both experimentally and theoretically [8], the studies indicated strong ionic metal-ligand bonding in La-C3CA complex and insignificant donor acceptor interaction. A sensitized emission and an effective ligand to metal energy transfer in the samarium complex with 7-acetoxy coumarin 3-carboxylic acid [9], and efficient emission with long lifetimes although with low quantum yield values in the systems of $\mathrm{Eu}^{3+}$ and $\mathrm{Tb}^{3+}$ with crown ethers and iminodiacetic subunits attached to 3 -aroylcoumarins in methanol [10] have been observed. The samarium (III) complex of coumarin-3-carboxylic acid proved to be the most active antiproliferative agent among the complexes [11]. Erbium (III) and europium (III) luminescent lanthanide complexes based on a coumarin showing effective energy transfer between the coumarin ligand and the lanthanide ions were designed and characterized by Kim et al. [12].

Coumarin derivatives have been a subject of electrochemiluminescence its mechanisms, induced by injection of hot electrons into aqueous electrolyte solution [13]. The studies showed that coumarins can be suitable candidates as ECL labels for bioaffinity assays or other analytical applications [13].

In our recent investigations, we have applied specific electrogenerated luminescence, ECL, which can be observed in $\mathrm{Ln}(\mathrm{III})(\mathrm{Ln}=\mathrm{Tb}$, Dy and $\mathrm{Eu})$ complexes with organic ligands containing aromatic rings forming stable complexes, in studying mechanisms of energy transfer $[14,15]$. The ECL was obtained by producing highly oxidizing and reducing species as: hydrated electrons, hydroxyl, and sulfate radicals. These strong redox reactants efficiently excite the complexed Ln (III) ions by ligand to metal energy transfer. 


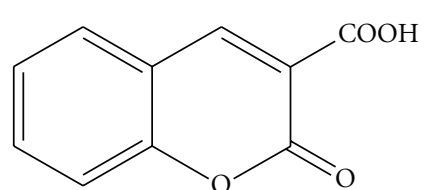

FIGURE 1: The structure of the ligand (coumarin-3-carboxylic acid, C3CA) studied.

The present work contains results of photoluminescence (PL) and electrochemiluminescence (ECL) studies concerning the complex of Eu (III) with the C3CA ligand. The goal of these studies was to show the possibility of ECL generation with the use of electroexcitation resulting in the ligandto-metal energy transfer (LMET) in aqueous solution with participation of the Eu (III) ion.

\section{EXPERIMENTAL}

\subsection{Synthesis of compounds}

All chemicals were used of AR grade. The europium oxide $\mathrm{Eu}_{2} \mathrm{O}_{3}$ (Merck 99.99\%, KGaA, Germany) was dissolved in a slight excess of $\mathrm{HNO}_{3}$ or $\mathrm{H}_{2} \mathrm{SO}_{4}$. Obtained europium nitrate was dried and its appropriate amount dissolved in ethanol (spectroscopic grade) and europium sulphate was dried and dissolved in water (doubly distilled).

Synthesis of Eu(III) complex with coumarin-3-carboxylic acid.

The complex was synthesized by reaction of the Eu (III) salt, $\mathrm{Eu}\left(\mathrm{NO}_{3}\right)_{3}$, with coumarin-3-carboxylic acid (Merck, Figure 1) in a 1:2 metal to ligand molar ratio. The complex was prepared by adding ethanol solution of $\mathrm{Eu}\left(\mathrm{NO}_{3}\right)_{3}$ into ethanol solution of the ligand. The reaction mixture was stirred for 2 hours at room temperature. The precipitate was filtered, washed four times with ethanol, and dried in a desiccator to constant weight. The obtained Eu/C3CA complex was very limited soluble in water and ethanol $\left(<10^{-4} \mathrm{~mol} \times \mathrm{dm}^{3}\right)$.

\subsection{Methods}

The carbon, hydrogen, and nitrogen content of the compounds were determined by elemental analysis on an elemental analyser model VARIO ELIII. The IR spectra (4000$400 \mathrm{~cm}^{-1}$ ) were obtained by means of an FTIR Bruker IFS $113 \mathrm{v}$ spectrophotometer (resolution $1 \mathrm{~cm}^{-1}$ ), and the samples $(\sim 2 \mathrm{mg})$ were prepared in $\mathrm{KBr}$. The water content was determined by luminescence lifetime measurement of the solid complex and was confirmed by TGA.

The luminescence lifetime measurements were carried out using the detection system consisting of a nitrogen laser (KB6211) and a tuneable dye laser [16].

The fluorescence spectra were recorded using a PerkinElmer MP3 and Aminco Bowman AB2 spectrofluorimeters.

ECL measurements were carried out using the experimental setup described recently [14]. Detection of the emitting light was possible through the use of a spectrometer Triax 180 (Horiba Jobin YVON GmbH, Germany) and a photon-counting head Hamamatsu H4730-01. The spectrometer allows for spectral recording in the range of 200$800 \mathrm{~nm}$ with a step of $0.15 \mathrm{~nm}$. The spectrometer control is executed using a built-in digital controller. This controller enables one to operate the position of a diffraction grating and the width of the entrance and exit slits by controlling of the respective stepping motors. It also allows for sharp tuning of an emission wavelength and its change during measurements. The detection module of this system also allows the measurements of ultra weak emission (chemiand electrochemiluminescence) spectra with a standard resolution of a moderate quality spectrofluorimeter. The recording module of this equipment consists of a photoncounting head Hamamatsu H4730-01 and a scalar cart attached to a PC. The ECL spectra, because of their weak emission, were recorded using the method of cut-off filters [17]. The ECL measurements were made in a double electrode system: $\mathrm{Al} / \mathrm{Al}_{2} \mathrm{O}_{3}$ as the working electrode and a Pt-wire as the counter electrode, in aqueous solution. The aluminium plate electrode $(5 \mathrm{~mm} \times 25 \mathrm{~mm} \times 1 \mathrm{~mm})$ was covered with a natural oxide film (ca. $2 \mathrm{~nm}$ thick) and was made of an aluminium stripe (99.999\%, Merck). The platinum anode was made of a $\mathrm{Pt}$-wire ( $1.5 \mathrm{~mm}$ diameter). The ECL measurements were recorded with the use of the earlier described equipment [14].

\section{RESULTS AND DISCUSSION}

Characterization of the Eu (III) complex with coumarin-3carboxylic acid.

The elemental analysis of the Eu/C3CA compound showed the following data: $\mathrm{C}=39.07 \% ; \mathrm{H}=2.14 \%$; $\mathrm{N}=2.16 \%$, which are in a very good agreement with the calculated values, $\mathrm{C}=38,23 \% ; \mathrm{H}=2.25 \% ; \mathrm{N}=2.24 \%$, for $\mathrm{Eu}$ $(\mathrm{C} 3 \mathrm{CA})_{2}\left(\mathrm{NO}_{3}\right)\left(\mathrm{H}_{2} \mathrm{O}\right)_{2}, \mathrm{EuC} 20 \mathrm{H} 14 \mathrm{NO} 13$. The formation of this Eu (III) complex was also confirmed by IR spectroscopy (see Figure 2) and luminescence of lifetime measurement.

\subsection{FTIR spectra analysis}

Detailed analysis of vibrational frequencies, the IR spectra of the HC3CA ligand and its Eu (III) complex, showed a very good agreement with the literature data [8] and gave evidence for bidentate coordination of C3CA ligand to Eu (III) ions through the carbonylic oxygen and the carboxylic oxygen. The bands in the $3580-3440 \mathrm{~cm}^{-1}$ range are observed in the $\mathrm{Eu} / \mathrm{C} 3 \mathrm{CA}$ complex IR spectrum due to the $v(\mathrm{OH})$ modes of the coordinated water molecules, while the broad band at $\sim 3180 \mathrm{~cm}^{-1}$ in the IR spectrum of the ligand is assigned to the $v(\mathrm{OH})$ vibrational mode. This band is not observed in the spectra of the complexes, indicating that the deprotonated ligand form participates in the complexes.

The following bands, observed in the IR spectra of the $\mathrm{Eu} / \mathrm{C} 3 \mathrm{CA}$ complex, are assigned to the vibrational modes of the $\mathrm{NO}_{3}$ group: $1260 \mathrm{~cm}^{-1}$ for $\nu(\mathrm{NO})_{\text {bonded }} ; 790 \mathrm{~cm}^{-1}$ and $725 \mathrm{~cm}^{-1}$ for $\delta(\mathrm{ONO})$. These bands indicate the presence of the nitrate group in the Eu/C3CA complex molecule. On the basis of the above detailed vibrational study, we 


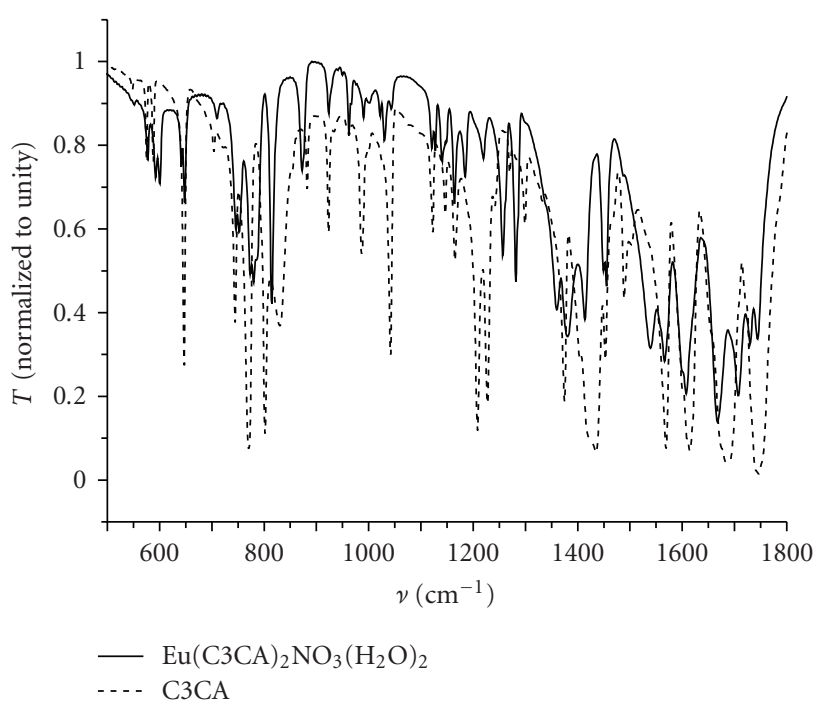

(a)

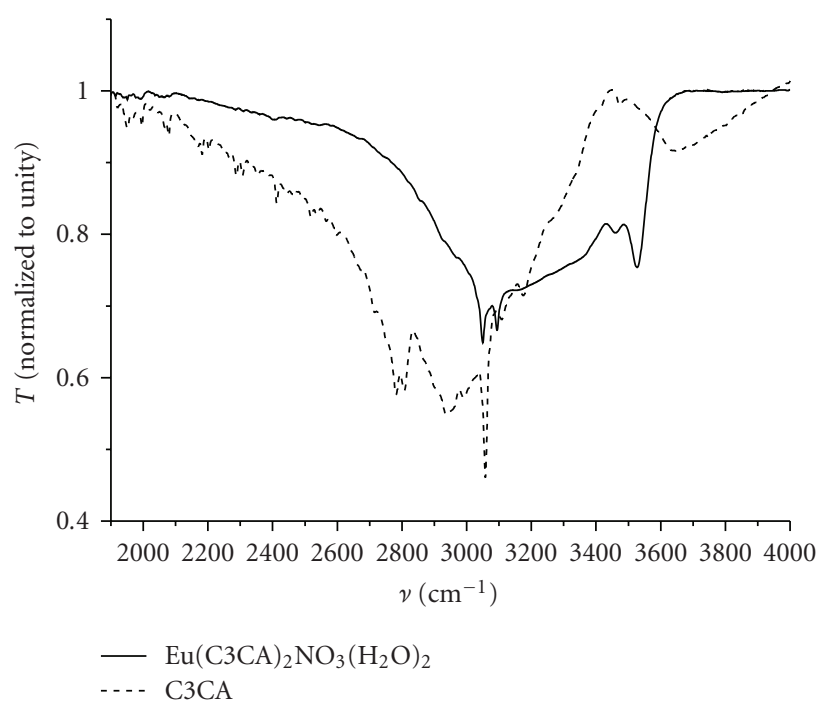

(b)

FIgURE 2: FTIR spectra of the C3CA ligand and $\mathrm{Eu}(\mathrm{C} 3 \mathrm{CA})_{2}\left(\mathrm{NO}_{3}\right)$ $\left(\mathrm{H}_{2} \mathrm{O}\right)_{2}$ complex recorded in the range of $500-1800 \mathrm{~cm}^{-1}$ (a) and 2000 and $4000 \mathrm{~cm}^{-1}$ (b).

can conclude that the metal-ligand bonding in $\mathrm{Eu}(\mathrm{III})$ complexes of coumarin-3-carboxylic acid appeared to be strongly ionic with very small donor-acceptor character, which is in agreement with the previously reported data for the Gd (III), Sm (III), and Dy (III) complexes with the C3CA ligand [11].

\subsection{Luminescence and electrochemiluminescence studies}

The $\mathrm{Eu}(\mathrm{III})$ luminescence lifetime measured as $411 \pm 6$ microseconds (average of 6 measurements) for the solid $\mathrm{Eu} / \mathrm{C} 3 \mathrm{CA}$ complex was used to calculate the number of water molecules, bond in the inner sphere of the $\mathrm{Eu}(\mathrm{III})$ ion, from the equation below [18]:

$$
\mathrm{n}_{\mathrm{H}_{2} \mathrm{O}}=1.05 \times \tau^{-1}-0.7
$$

The decay rate $(\mathrm{k}=1 / \tau, \tau$ in milliseconds) of the $5 \mathrm{D}_{0} \rightarrow 7 \mathrm{~F}_{\mathrm{j}}$ emission is proportional to the number of aqua ligands, coordinating the $\mathrm{Eu}(\mathrm{III})$ ion, due to the vibronic coupling of the $5 \mathrm{D}_{0}$ excited state with vibrational states of the high frequency $\mathrm{OH}$ oscillators of the aqua ligands. The calculated $\mathrm{n}_{\mathrm{H}_{2} \mathrm{O}}$ based on the value of $\tau$ (0.411 millisecond) measured for the Eu/C3CA complex indicates the presence of two water molecules in the $\mathrm{Eu}($ III) inner coordination sphere. This hydration number $\left(\mathrm{n}_{\mathrm{H}_{2} \mathrm{O}} \approx 2\right)$ confirms the formula $\mathrm{Eu}(\mathrm{C} 3 \mathrm{CA})_{2}\left(\mathrm{NO}_{3}\right)\left(\mathrm{H}_{2} \mathrm{O}\right)_{2}$ of the complex-formed $\mathrm{Eu}(\mathrm{III})$ with coumarin-3-carboxylic acid ligand. The studied complex $\mathrm{Eu}(\mathrm{C} 3 \mathrm{CA})_{2}\left(\mathrm{NO}_{3}\right)\left(\mathrm{H}_{2} \mathrm{O}\right)_{2}$ is weakly soluble in water and alcohol $\left(<10^{-4} \mathrm{~mol} / \mathrm{dm}^{3}\right.$ in water $)$.

The electrochemiluminescence of the europium(III) ion is the least known among the lanthanide series $[13,19]$. Studies being done so far, considering europium chelates with the use of cathodic-generated ECL in aqueous solution, indicate two possible mechanisms of excitation of the $\mathrm{Eu}(\mathrm{III})$ ions: (1) in the process of energy transfer from electrochemically exited ligand the $\mathrm{Eu}(\mathrm{III})$ ion, or (2) in the electroreduction process of $\mathrm{Eu}^{3+}$ to $\mathrm{Eu}^{2+}$ following its oxidation with the use of a strong radical oxidizer generated as a result of decomposition of a coreactant (e.g., $\mathrm{S}_{2} \mathrm{O}_{8}{ }^{2-}$ ). It has been previously shown that this oxidizing excitation process of $\mathrm{Eu}(\mathrm{II})$ occurs mainly in chemiluminescence systems [20, 21].

Luminescence excitation and emission spectra of the solid $\mathrm{Eu}(\mathrm{C} 3 \mathrm{CA})_{2}\left(\mathrm{NO}_{3}\right)\left(\mathrm{H}_{2} \mathrm{O}\right)_{2}$ complex are presented in Figure 3. These photoluminescence studies show that the emission spectrum of the complex $\left(\lambda_{\mathrm{ex}}=370 \mathrm{~nm}\right)$ exhibits typical narrow sharp emission bands corresponding to the characteristic ${ }^{5} \mathrm{D}_{0} \rightarrow{ }^{7} \mathrm{~F}_{\mathrm{j}}$ transition of $\mathrm{Eu}(\mathrm{III})$ ion with the strongest emission band of the characteristic ${ }^{5} \mathrm{D}_{0} \rightarrow{ }^{7} \mathrm{~F}_{2}$ transition of the $\mathrm{Eu}(\mathrm{III})$ ion at $615 \mathrm{~nm}$. This observation confirms the crucial role of the C3CA ligand in the transfer of the absorbed energy to the central ion of the complex.

In order to find optimal conditions for the ECL process, we studied the dependence of $\mathrm{pH}$ on the photoluminescence (PL) intensity of $\mathrm{Eu}(\mathrm{III})$ in the solution of $\mathrm{Eu} / \mathrm{C} 3 \mathrm{CA}$ complex. As shown in Figure 4, the PL intensity of Eu(III) in the complex solution considerably decreases above the value of $\mathrm{pH}>5$ with a simultaneous change of the intensity ratio of the bands ${ }^{5} \mathrm{D}_{0} \rightarrow{ }^{7} \mathrm{~F}_{1}$ and ${ }^{5} \mathrm{D}_{0} \rightarrow{ }^{7} \mathrm{~F}_{2}$. The observed changes, especially in the range of $\mathrm{pH}>6$, indicate ligand replacements in the inner coordination sphere of the Eu(III) ion, due to progressive hydrolysis occurring in the aqueous solution of the complex.

The ECL studies of systems containing the $\mathrm{Eu}(\mathrm{III})$ ion, both in the complex with C3CA ligand and uncomplexed (as $\left.\mathrm{Eu}_{2}\left(\mathrm{SO}_{4}\right)_{3}\right)$, were investigated.

The quantum yield of the ECL utraweak emission is assessed (as $\sim 5 \times 10^{-8}$, for $\mathrm{Eu}_{2}\left(\mathrm{SO}_{4}\right)_{3}$ ). The quantum yield of this utraweak emission is given as the ratio of the number of electric charges introduced into the system, resulting of ECL process, to the number of photons generated in the 


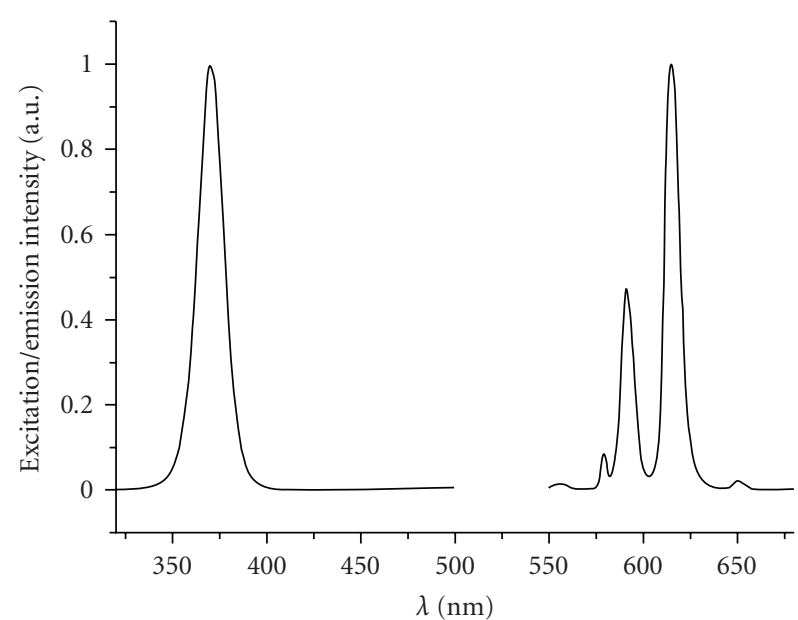

FIgURE 3: Normalized excitation and emission spectra of solid state of $\mathrm{Eu}(\mathrm{C} 3 \mathrm{CA})_{2}\left(\mathrm{NO}_{3}\right)\left(\mathrm{H}_{2} \mathrm{O}\right)_{2}$ complex $\left(5 \times 10^{-5} \mathrm{~mol} \times \mathrm{dm}^{-3}\right), \lambda_{\text {exc }}=$ $365 \mathrm{~nm}$.

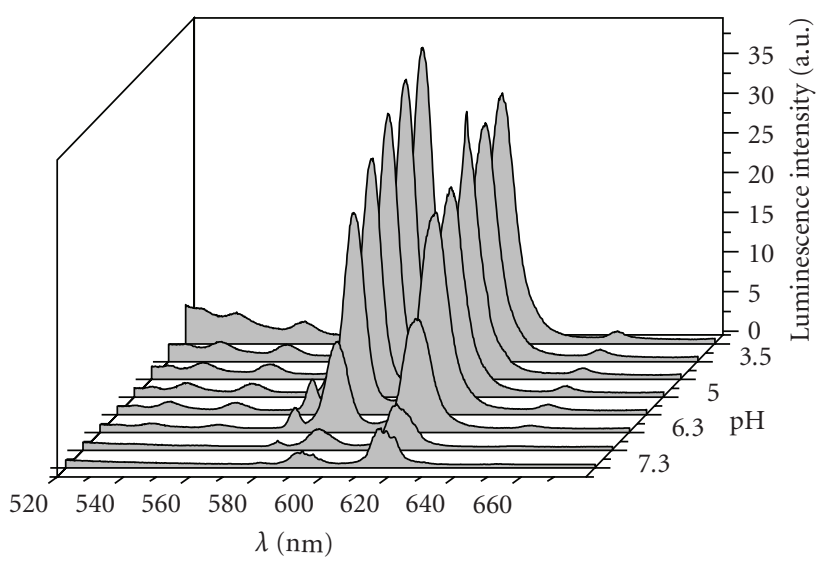

FIGURE 4: Photoluminescence spectrum of aqueous solution of $(5 \times$ $\left.10^{-5} \mathrm{~mol} \times \mathrm{dm}^{-3}\right), \lambda_{\text {exc }}=355 \mathrm{~nm}$ as a function of $\mathrm{pH}$.

process, in the same geometrical conditions. The excitation mechanism of the coumarin 3-carboxylic acid molecules via the ECL method involves emission of "hot" electrons from the electrode into the $\mathrm{Eu}(\mathrm{III})$ complex. This assists in the formation of active radicals on the electrode surface in solutions containing peroxodisulfate $\mathrm{S}_{2} \mathrm{O}_{8}{ }^{2-}$ ions, as a coreactant, which can be easily decomposed in the following reaction:

$$
\mathrm{e}_{a q}^{-}+\mathrm{S}_{2} \mathrm{O}_{8}{ }^{2-} \longrightarrow \mathrm{SO}_{4}^{--}+\mathrm{SO}_{4}^{2-} .
$$

Under air-saturated solutions, and due to oxygen evolution at the counter electrode, oxyradicals and hydrogen peroxide can be formed, if hydrated electrons are produced at the working electrode [13]. The ECL spectra were recorded in aqueous solution containing: only the coreactant $\mathrm{K}_{2} \mathrm{~S}_{2} \mathrm{O}_{8}$ (Figure 5(a)), and $\mathrm{Eu}_{2}\left(\mathrm{SO}_{4}\right)_{3}$ (as uncomplexed $\mathrm{Eu}(\mathrm{III})$ ) plus the coreactant $\mathrm{K}_{2} \mathrm{~S}_{2} \mathrm{O}_{8}$ (see Figure 5(b)). The ECL spectra

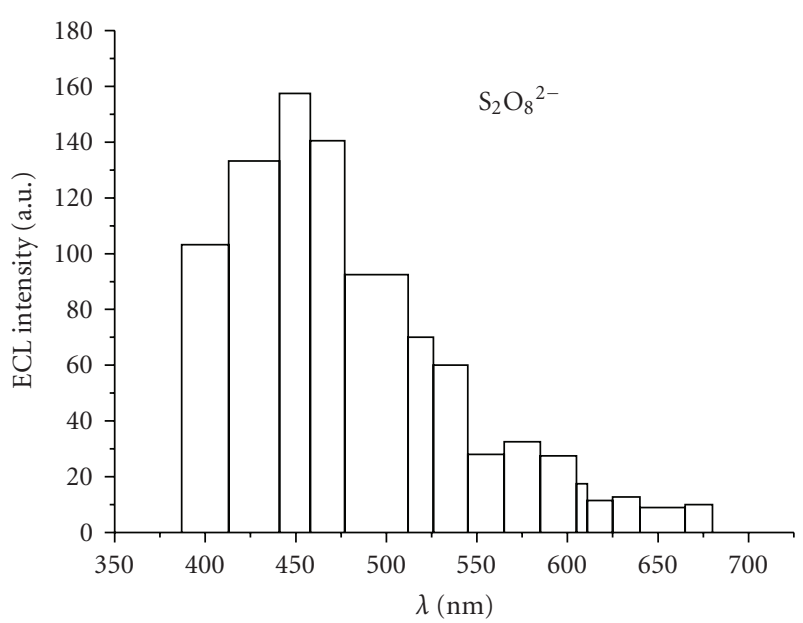

(a)

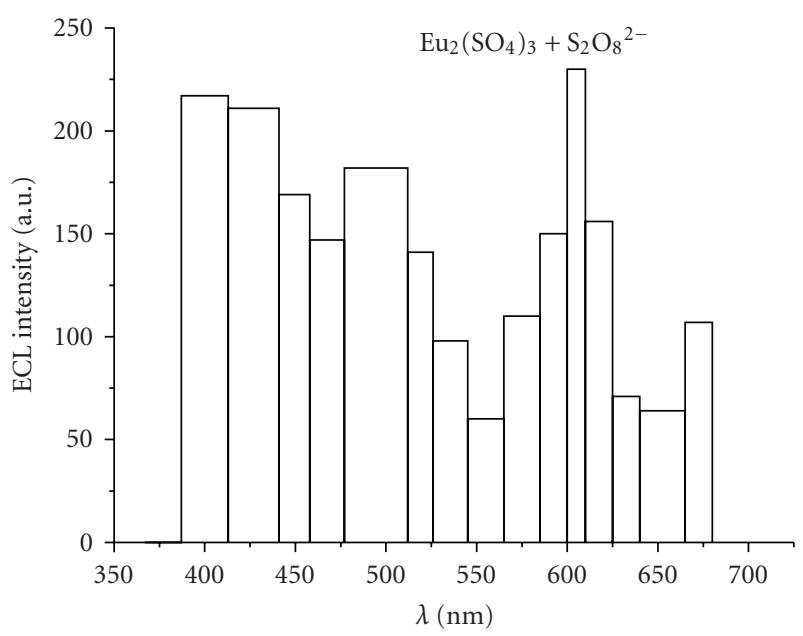

(b)

FIGURE 5: ECL spectra of system containing $\mathrm{K}_{2} \mathrm{~S}_{2} \mathrm{O}_{8}\left(2 \times 10^{-2} \mathrm{~mol}\right.$ $\left.\times \mathrm{dm}^{-3}\right)$. (a) and $\mathrm{K}_{2} \mathrm{~S}_{2} \mathrm{O}_{8}+\mathrm{Eu}_{2}\left(\mathrm{SO}_{4}\right)_{3}\left(5 \times 10^{-2} \mathrm{~mol} \times \mathrm{dm}^{-3}\right)$. (b) Experimental conditions: $\mathrm{Al} / \mathrm{Al}_{2} \mathrm{O}_{3}$ as a working electrode, $\mathrm{Pt}$ wire as a counter electrode, applied pulse voltage $-50 \mathrm{~V}$, frequency $40 \mathrm{~Hz}$, pulse charge $30 \mu \mathrm{C}$, pH of solution 4.5.

and spectral analysis, due to a very weak ECL intensity observed in the studied system, were complete using the method of cut-off filters [17].

In the case of ECL, spectrum recorded for the coreactant $\left(\mathrm{K}_{2} \mathrm{~S}_{2} \mathrm{O}_{8}\right)$ predominates a band with maximum at $\sim 450 \mathrm{~nm}$, corresponding to radiative relaxation from the ${ }^{3} \mathrm{P}$ excited state to the ${ }^{1} \mathrm{~S}$ ground state of the active $\mathrm{F}$-center in $\mathrm{Al}_{2} \mathrm{O}_{3}$ [22]. The ECL spectrum containing additionally the $\mathrm{Eu}(\mathrm{III})$ ions exhibits characteristic emission in the region around $600 \mathrm{~nm}$. The ECL spectrum characteristic for $\mathrm{Eu}(\mathrm{III})$, generated in the system without an organic ligand, shows that $\mathrm{Eu}(\mathrm{III})$ can be excited by the reduction-oxidation process. The $\mathrm{Eu}(\mathrm{III})$ ions are easily reduced to $\mathrm{Eu}(\mathrm{II})$ ( $\mathrm{E}_{0}$ for $\mathrm{Eu}(\mathrm{III}) / \mathrm{Eu}(\mathrm{II})=-0.35 \mathrm{~V})$ and then are oxidized by sulfate 


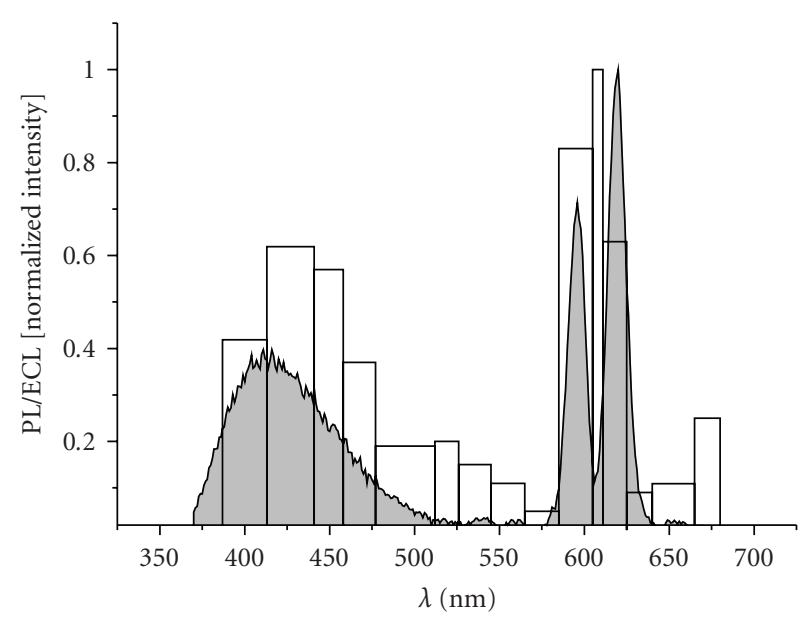

FIgURE 6: Photoluminescence $\left(\lambda_{\mathrm{exc}}=355 \mathrm{~nm}\right)$ and electrochemiluminescence spectra of $\mathrm{Eu}(\mathrm{C} 3 \mathrm{CA})_{2}\left(\mathrm{NO}_{3}\right)\left(\mathrm{H}_{2} \mathrm{O}\right)_{2}$ complex in aqueous solution. Experimental conditions: $\mathrm{Al} / \mathrm{Al}_{2} \mathrm{O}_{3}$ as a working electrode, $\mathrm{Pt}$ wire as a counter electrode, applied pulse voltage $-50 \mathrm{~V}$, frequency $40 \mathrm{~Hz}$, pulse charge $30 \mu \mathrm{C}, \mathrm{pH}$ of solution 4.5 , concentration of the complex $5 \times 10^{-5} \mathrm{~mol} \times \mathrm{dm}^{-3}$.

and hydroxyl radicals present in solution leading to $\mathrm{Eu}(\mathrm{III})$ excitation

$$
\begin{gathered}
e_{a q}^{-}+\mathrm{Eu}^{3+} \longrightarrow \mathrm{Eu}^{2+}, \\
\mathrm{Eu}^{2+}+\mathrm{SO}_{4}^{--} \longrightarrow \mathrm{SO}_{4}^{2-}+\left(\mathrm{Eu}^{3+}\right)^{*} \\
\left(\mathrm{Eu}^{3+}\right)^{*} \longrightarrow \mathrm{Eu}^{3+}+\mathrm{h} \nu(595,615 \mathrm{~nm}) .
\end{gathered}
$$

The ECL spectrum of the $\mathrm{Eu}(\mathrm{C} 3 \mathrm{CA})_{2}\left(\mathrm{NO}_{3}\right)\left(\mathrm{H}_{2} \mathrm{O}\right)_{2}$ complex shows, additionally to the characteristic emission of Eu(III), also a broad emission band in the range of $370-500 \mathrm{~nm}$, corresponding to radiative transitions in the ligand molecule (see Figure 6). In the case of complexes containing phenyl $\operatorname{group}(\mathrm{s})$, the radical excitation of the aromatic ring can be accomplished on the way of redox reactions. Therefore, the studied system consisting of $\mathrm{Eu}(\mathrm{C} 3 \mathrm{CA})_{2}\left(\mathrm{NO}_{3}\right)\left(\mathrm{H}_{2} \mathrm{O}\right)_{2}$ complex and $\mathrm{S}_{2} \mathrm{O}_{8}{ }^{2-}$ the central ion can be potentially excited according to two ways:

(I) as a result of energy transfer from the excited state (singlet or triplet) of the ligand to the $\mathrm{Eu}(\mathrm{III})$ ion:

$$
\begin{gathered}
\mathrm{Eu}(\mathrm{III})-\mathrm{L}+\mathrm{SO}_{4}^{\cdot-} \longrightarrow \mathrm{Eu}(\mathrm{III})-\mathrm{L}_{\mathrm{OX}}+\mathrm{SO}_{4}^{2-}, \\
\mathrm{Eu}(\mathrm{III})-\mathrm{L}_{\mathrm{OX}}+e_{a q}^{-} \longrightarrow \mathrm{Eu}-\mathrm{L}^{*}, \\
\mathrm{Eu}-\mathrm{L}^{*} \longrightarrow \mathrm{Eu}^{*}-\mathrm{L} \longrightarrow \mathrm{Eu}-\mathrm{L}+\mathrm{h} \nu(595,615 \mathrm{~nm}),
\end{gathered}
$$

(II) on the way of reduction and oxidation of the complexed Eu(III):

$$
\begin{gathered}
e_{a q}^{-}+\mathrm{Eu}(\mathrm{III})-\mathrm{L} \longrightarrow \mathrm{Eu}(\mathrm{III})-\mathrm{L}_{\mathrm{RED}}, \\
\mathrm{Eu}(\mathrm{III})-\mathrm{L}_{\mathrm{RED}} \longrightarrow \mathrm{Eu}(\mathrm{II})-\mathrm{L}, \\
\mathrm{Eu}(\mathrm{II})-\mathrm{L}+\mathrm{SO}_{4}^{--} \longrightarrow \mathrm{Eu}(\mathrm{III})^{*}-\mathrm{L}+\mathrm{SO}_{4}^{2-}, \\
\mathrm{Eu}^{*}-\mathrm{L} \longrightarrow \mathrm{Eu}-\mathrm{L}+\mathrm{h} \nu(595,615 \mathrm{~nm}) .
\end{gathered}
$$

The ECL intensity $(\lambda=615 \mathrm{~nm})$ observed in the system containing the complex studied is over one order of magnitude higher than in that with the uncomplexed $\mathrm{Eu}(\mathrm{III})$ ions. This observation proves the predominate role of the ligand to metal energy transfer on the total efficiency of the electrochemiluminescence.

\section{CONCLUSIONS}

$\mathrm{Eu}(\mathrm{III})$ forms with the ligand of coumarin-3-carboxylic acid (C3CA) the complex of composition $\mathrm{Eu}(\mathrm{C} 3 \mathrm{CA})_{2}\left(\mathrm{NO}_{3}\right)\left(\mathrm{H}_{2} \mathrm{O}\right)_{2}$. This complex is one of a few examples in which ECL characteristic for the $\mathrm{Eu}(\mathrm{III})$ ion can be observed $[13,15,19]$. The mechanism of excitation of the central ion can be completed as a result of energy transfer from the excited state of the ligand to the $\mathrm{Eu}(\mathrm{III})$ ion (LMET), which is predominant, and on the way of reduction and oxidation reactions of the complexed $\mathrm{Eu}(\mathrm{III})$ ion. The observed ECL in this system is utraweak, due to a very limited solubility of C3CA, and therefore can be detected with the use of a single photon counting method. Coumarin derivatives having important biological activities, of better than C3CA solubility in aqueous solution should exhibit more intensive ECL. This ECL generated with the participation of the LMET, can be potentially used in analytical applications of biologically active agents, for example, in pharmaceutical preparations, as we recently have shown using the chemically generated emission for the determination of tetracycline derivatives [23].

\section{REFERENCES}

[1] G. Kokotos, V. Theodorou, C. Tzougraki, D. Deforce, and E. Van den Eeckhout, "Synthesis and in vitro cytotoxicity of aminocoumarin platinum(II) complexes," Bioorganic \& Medicinal Chemistry Letters, vol. 7, no. 17, pp. 2165-2168, 1997.

[2] A. Karaliota, O. Kretsi, and C. Tzougraki, "Synthesis and characterization of a binuclear coumarin-3-carboxylate copper(II) complex," Journal of Inorganic Biochemistry, vol. 84, no. 1-2, pp. 33-37, 2001.

[3] I. Kostova, I. Manolov, I. Nicolova, S. Konstantinov, and M. Karaivanova, "New lanthanide complexes of 4-methyl-7hydroxycoumarin and their pharmacological activity," European Journal of Medicinal Chemistry, vol. 36, no. 4, pp. 339347, 2001.

[4] T. Wolff and H. Görner, "Photodimerization of coumarin revisited: effects of solvent polarity on the triplet reactivity and product pattern," Physical Chemistry Chemical Physics, vol. 6, no. 2, pp. 368-376, 2004.

[5] S. W. Ng and V. G. Kumar Das, "Tetramethylammonium bis(coumarin-3-carboxylato)triphenylstannate ethanol solvate," Acta Crystallographica C, vol. 53, no. 8, pp. 10341036, 1997.

[6] S. W. Ng, "Coordination complexes of triphenyltin coumarin3-carboxylate with $\mathrm{O}$-donor ligands: (coumarin-3-carboxylato)triphenyltin- $L$ ( $L=$ ethanol, diphenylcyclopropenone and quinoline $N$-oxide) and bis[(coumarin-3-carboxylato)triphenyltin]- $L$ ( $L=$ triphenylphosphine oxide and triphenylarsine oxide)," Acta Crystallographica C, vol. 55, no. 4, pp. 523-531, 1999. 
[7] A. L. El-Ansary and M. M. Omar, "Formation constants and molecular structure of vanadium (IV), cobalt (II), nickel (II), copper (II) and zinc (II) chelates with 8-(arilazo)-7-hydroxy4-methylcoumarin dyes," Egyptian Journal of Chemistry, vol. 31, pp. 511-520, 1988.

[8] Tz. Mihaylov, N. Trendafilova, I. Kostova, I. Georgieva, and G. Bauer, "DFT modeling and spectroscopic study of metalligand bonding in $\mathrm{La}$ (III) complex of coumarin-3-carboxylic acid," Chemical Physics, vol. 327, no. 2-3, pp. 209-219, 2006.

[9] E. Bakier and M. S. A. Abdel-Mottaleb, "Factors affecting light energy transfer in some samarium complexes," International Journal of Photoenergy, vol. 7, no. 1, pp. 51-58, 2005.

[10] M.-T. Alonso, E. Brunet, O. Juanes, and J.-C. Rodríguez-Ubis, "Synthesis and photochemical properties of new coumarinderived ionophores and their alkaline-earth and lanthanide complexes," Journal of Photochemistry and Photobiology A, vol. 147, no. 2, pp. 113-125, 2002.

[11] I. Kostova, G. Momekov, and P. Stancheva, "New samarium(III), gadolinium(III), and dysprosium(III) complexes of coumarin-3-carboxylic acid as antiproliferative agents," Metal-Based Drugs, vol. 2007, Article ID 15925, 8 pages, 2007.

[12] S.-G. Roh, N. S. Baek, K.-S. Hong, and H. K. Kim, "Synthesis and photophysical properties of luminescent lanthanide complexes based on coumarin-3-carboxylle acid for advanced photonic applications," Bulletin of the Korean Chemical Society, vol. 25, no. 3, pp. 343-344, 2004.

[13] M. Helin, Q. Jiang, H. Ketamo, et al., "Electrochemiluminescence of coumarin derivatives induced by injection of hot electrons into aqueous electrolyte solution," Electrochimica Acta, vol. 51, no. 4, pp. 725-730, 2005.

[14] K. Staninski, S. Lis, and D. Komar, "Electrochemiluminescence on $\mathrm{Dy}(\mathrm{III})$ and $\mathrm{Tb}(\mathrm{III})$-doped $\mathrm{Al} / \mathrm{Al}_{2} \mathrm{O}_{3}$ surface electrode," Electrochemistry Communications, vol. 8, no. 7, pp. 1071-1074, 2006.

[15] K. Staninski and S. Lis, "Electrogenerated luminescence of chosen lanthanide complexes at stationary oxide-covered aluminium electrode," Journal of Alloys and Compounds, vol. 451, no. 1-2, pp. 81-83, 2008.

[16] S. Lis, Z. Hnatejko, and Z. Stryla, "Device for measurements of selective luminescence excitation spectra of europium (III) based on a nitrogen and dye laser system," Optica Applicata, vol. 31, no. 3, pp. 643-648, 2001.

[17] M. Kaczmarek and S. Lis, "Luminescence characterisation of the reaction system histidine- $\mathrm{KBrO}_{3}-\mathrm{Tb}(\mathrm{III})-\mathrm{H}_{2} \mathrm{SO}_{4}$," Journal of Fluorescence, vol. 16, no. 6, pp. 825-830, 2006.

[18] P. P. Barthelemy and G. R. Choppin, "Luminescence study of complexation of europium and dicarboxylic acids," Inorganic Chemistry, vol. 28, no. 17, pp. 3354-3357, 1989.

[19] M. M. Richter and A. J. Bard, "Electrogenerated chemiluminescence. 58. Ligand-sensitized electrogenerated chemiluminescence in europium labels," Analytical Chemistry, vol. 68, no. 15, pp. 2641-2650, 1996.

[20] K. Staninski, M. Kaczmarek, and M. Elbanowski, "Kinetic and spectral aspects in chemiluminescence system $\mathrm{Eu}(\mathrm{III}) / \mathrm{HCO}_{3}^{-} / \mathrm{H}_{2} \mathrm{O}_{2}$," Journal of Alloys and Compounds, vol. 380, no. 1-2, pp. 177-180, 2004.

[21] M. Elbanowski, B. Mąkowska, K. Staninski, and M. Kaczmarek, "Chemiluminescence of systems containing lanthanide ions," Journal of Photochemistry and Photobiology A, vol. 130, no. 2-3, pp. 75-81, 2000.

[22] A. Hakanen, E. Laine, M. Latva, T. Ala-Kleme, and K. Haapakka, "Quenching of cathodic electrogenerated F-center luminescence of aluminium oxide by lanthanide cations at the electrode/electrolyte interface," Journal of Alloys and Compounds, vol. 275-277, pp. 476-479, 1998.

[23] M. Kaczmarek, A. Idzikowska, and S. Lis, "Europiumsensitized chemiluminescence of system tetracycline- $\mathrm{H}_{2} \mathrm{O}_{2}$ $\mathrm{Fe}(\mathrm{II}) /(\mathrm{III})$ and its application to the determination of tetracycline," to appear in Journal of Fluorescence. 


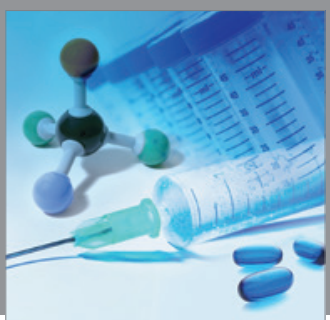

International Journal of

Medicinal Chemistry

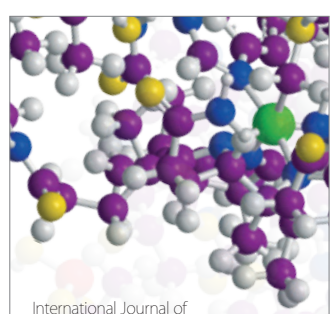

Carbohydrate Chemistry

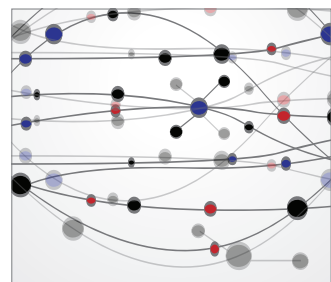

The Scientific World Journal
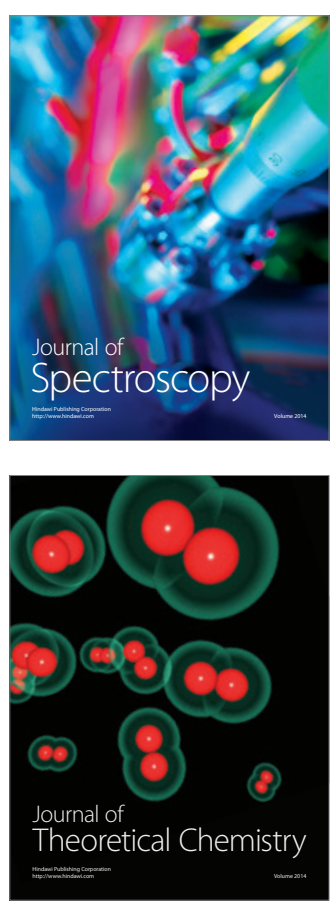
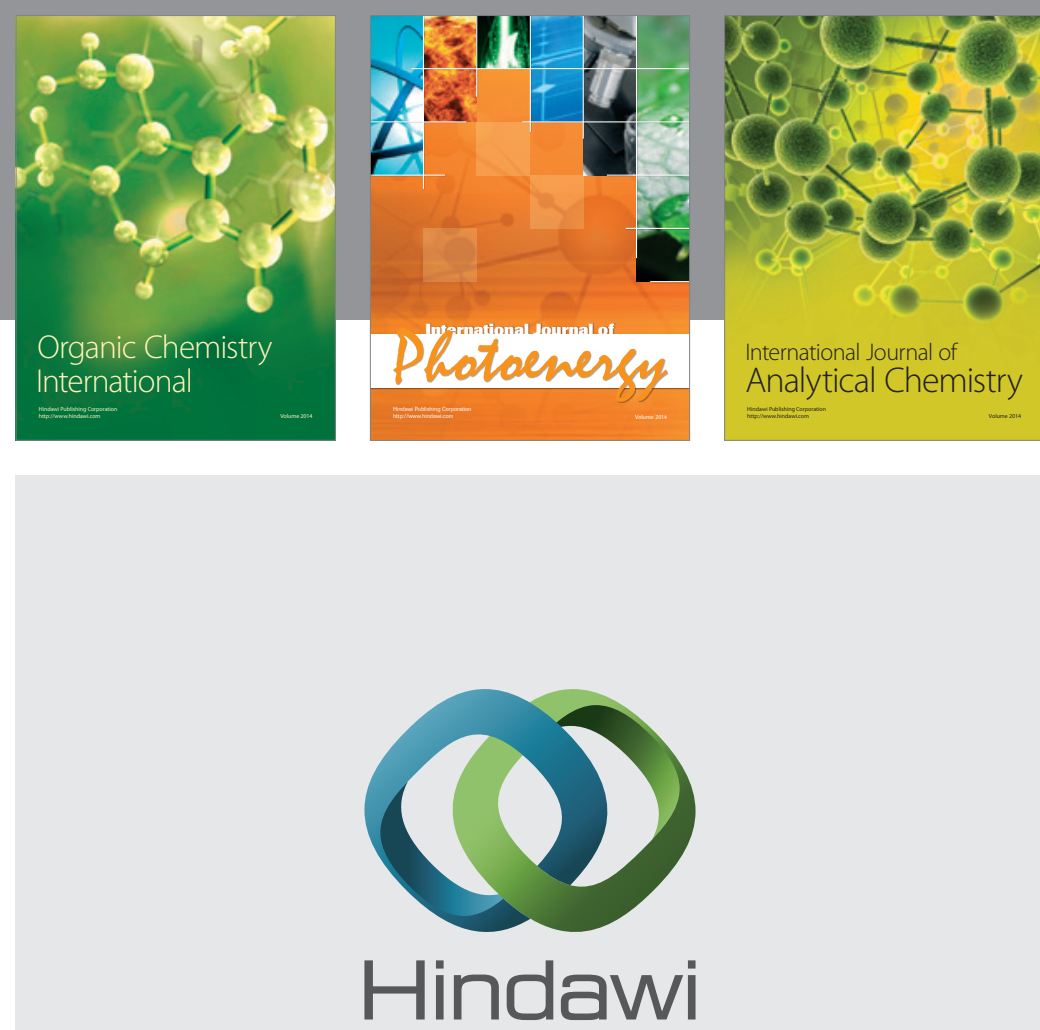

Submit your manuscripts at

http://www.hindawi.com
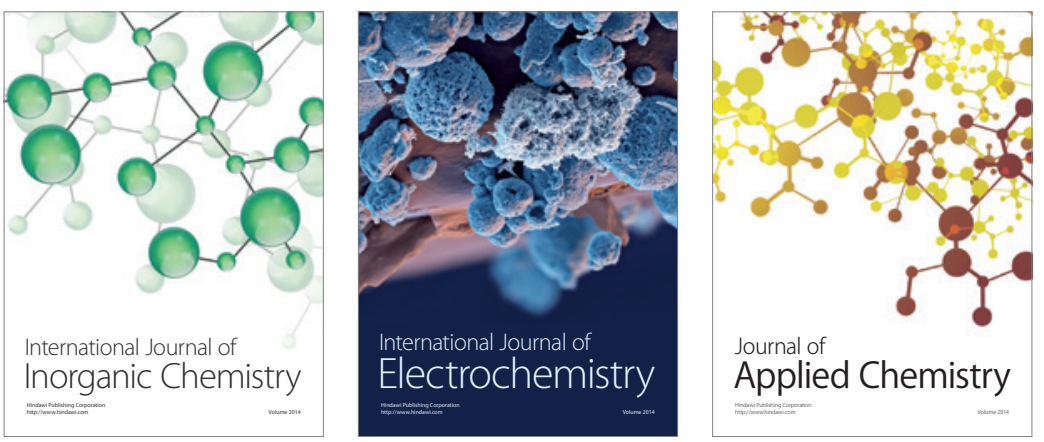

Journal of

Applied Chemistry
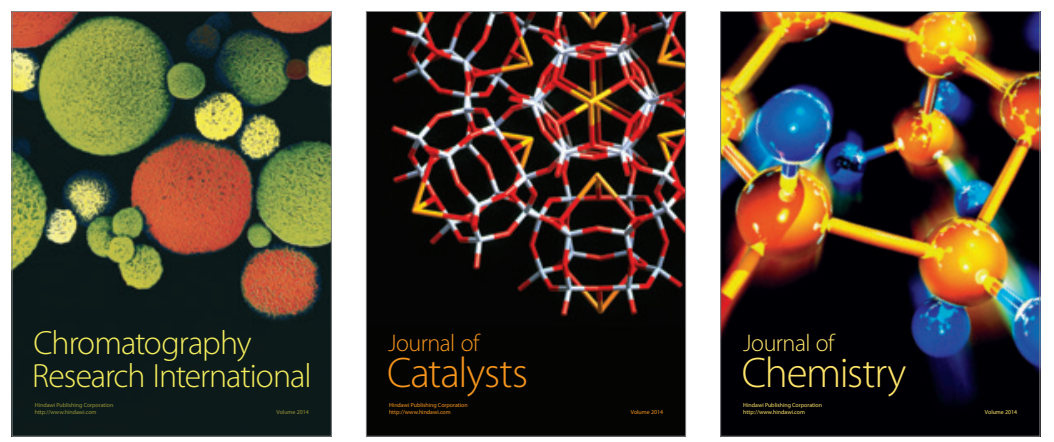
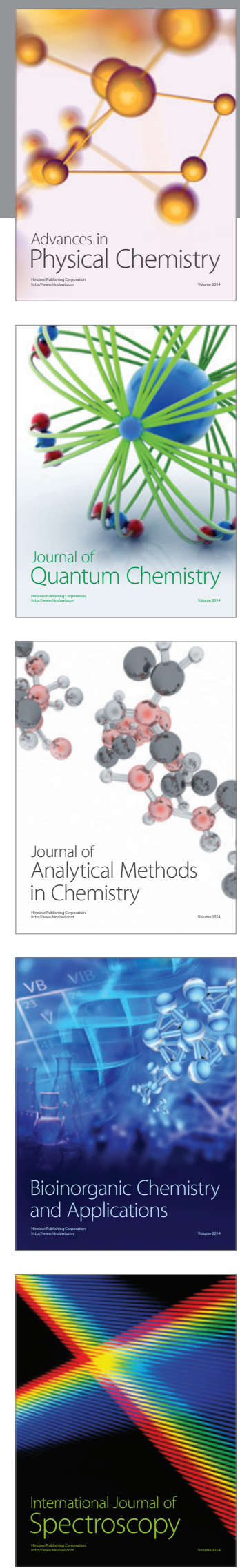